\title{
Assessment of the Prospects, Successes and Implementation Challenges of Performance Management System at the University of Health and Allied Sciences, Ho Ghana
}

\author{
Sarah Hackman ${ }^{1^{*}} \quad$ Erasmus Tetteh-Bator ${ }^{2}$ \\ 1.Academic Affairs, University of Health and Allied Sciences, Sokode-Lokoe, Ho, Ghana. \\ 2.Department of Mathematics and Statistics, University of South Florida, 4202 E Fowler Ave, Tampa, FL, USA.
}

\begin{abstract}
This research work was to assess the prospects, successes and implementation challenges of performance management system at University of Health and Allied Sciences (UHAS) in the Volta Region of Ghana. The study employed qualitative research design for the study. In-depth Interview method was the chosen research instrument to aid in data collection process. The study employed twenty-five (25) respondents who doubles as employees of the university and serving under various sections and units, like the office of the Vice Chancellor and registrar, human resource, finance, admissions office and staff of various schools or colleges as its unit of analysis. The research found that, performance management at the university has brighter prospects and thus is managed through a system of employee assessment which has resulted in some successes of the system being achieved in relation to human resource management in the areas of accountability, employee needs' identification, effective human resource management, promotions and efficient service delivery. Again, results showed the absence of feedback, annual system and performance management system conducted for promotional purposes as part of various challenges impeding the effectiveness of the system. As a result, the research recommended the design and implementation of a feedback system, regular employee assessment system and implementation of effective and efficient performance assessment system instead of mere annual appraisal system in the university.
\end{abstract}

Keywords: Performance Management System, Employee Assessment, Human Resource Management, In-depth Interview, Prospects, Implementation Challenges.

DOI: $10.7176 / \mathrm{PPAR} / 11-4-04$

Publication date:May $31^{\text {st }} 2021$

\section{Introduction}

Employee performance is a necessary requirement for organizational survival. Regardless of one's place of work in terms of the nature, size, organogram, characteristics, the kind of job and other related matters in organizational settings, employee performance becomes the archive heels and most critical part of organizational performance ones there are employees in place. (Church and Waclawski, 2009), However, provision of quality service to the principal welfare of any organization has become a problem in the public service. This has an undesirable effect on the level of service delivery. The quest to improve employee performance at the organisational level, increase productivity on the part of individual employees and teams has led to the civil service as well as individual private organizations instituting several schemes and measures. One such measure has been the introduction of performance management systems in organizations.

Employee performance management is a gradual process that seeks to identify, measure build performance of individual employees as well as teams at the organizational level and which aligns performance with the strategic goals and vision of the organization. Thus far, employee performance has a positive relationship with organizational goals. (Aguinis, 2014).

The primary objective of performance management systems is to identify employee weakness and improve performance over time. Managing employee performance has been identified as one of the achille heels of organizational strength and performance. This is because, human resources are considered the most important resources in organizational management as it seeks to employ or make use of other organizational resources (Candy, 2004 \& Pulakos, 2009). Despite such recognition of performance and human resource management at organizational settings, studies have established that, less than a third of employees believe their organization performance management systems assist in improving their performance and performance management for that matter ranks low in amongst the topics in employee satisfaction survey (Pulakos, 2009).

The quest for a shift and attention from other organizational resources to human resources with its attendant evolution of performance management has been occasioned by the contemporary challenges bedeviling organizations and human resource management for that leading to the search for dealing with the evolved problems, (Burchner, 2007). The presence of performance management schemes thus offers opportunity for integration of various human resource schemes for managing performance. (Armstrong, 2000) contended that, the evolution of performance management systems in organizations gives room for the introduction and 
subsequent integration of HR schemes and strategies that seeks to complement organization's HR architecture attain desired results and performances (Pfeffer, 1998).

Attaining increased performance and productivity has been the major objective of performance management systems, the world all over, studies have shown that task and contextual factors must be taken into account in a good performance management system. (Kuvas, 2007) reported that intrinsic motivation played a key role between the relationship of organizational goal setting and feedback on hand and self-reported performance on the other hand. In organizations that use performance as basis for pay and other related HR decisions, performance management systems must be managed fairly and equitably (Pulakos, 2004).However, the attempt to implement a robust performance management system that will institutionalize a performancedriven culture in both private and public-sector organizations has been a difficult and arduous task and bound to face some challenges (Fryer et al, 2009; Halachmi, 2011). Lack of top management commitment, lack of adequate understanding and support, lack of adequate resources, negative attitude towards the system, poor organization culture, lack of employee involvement are some of the challenges to hamper the implementation of performance management system in an organization (Fryer et al, 2009; Halachmi, 2011).

In the case of Ghana, empirical studies suggest that, performance management has been implemented in most organizations both public and private and that performance management framework was proposed in the year 2007. The primary objective of such policy initiative by the government was to build up systems and mechanisms for evaluating public sector employees particularly those at the helm of affairs like Chief Directors and Directors, (Appiah-Adu \& Aning 2012). The system also sought to attain standardization in the public sector and to provide a strategy for compensating better performances. Despite the seeming clear objectives of the policy introduction in the public service of Ghana, studies indicate that government support for the policy was minimal. For instance, Ohemeng (2012) reported that, cabinet of Ghana at the time did not support the policy due to several factors. Among the list of factors, Ohemeng, (2012); Ohemeng and Owusu, (2011) identified as "the first reason was that the draft policy was finished close to the end of the last term of the President, considering that the attention of the President was more on the elections than improving upon the administrative system of the country.

The second reason was that, there is high rate of turnover among Heads of the Civil Service. They believe that the frequent changes in the leadership of the service has in one way or the other contributed to Ghana's inability to adopt a policy on performance management". Despite this, performance management in the public sector has been introduced for some time in Ghana In Ghana today, performance management has attracted much attention in the public service. Public higher educational institutions have also made attempts to implement performance management systems to achieve the objectives of their organizations. However, cconcerns have been raised against the wholesale importation of performance management systems into public higher educational institutions which are classified as not for profit without regard for consideration of the particular context of public universities (Cheverton, 2007).

The University of Health and Allied Sciences case is of no difference. The University of Health and Allied Sciences was established five years ago by an Act of Parliament (ACT 828, 2011) as a public university in Ghana. Since its inception, the University of Health and Allied Sciences has implemented employee performance management system in order to align individual employee objectives to the strategic objectives of the University in order to be able to compete with other tertiary institutions in the country.

However, events in the institution seem to show that implementation has not been effective. Since the introduction and implementation of the performance management in the University, not much has been achieved in terms of employee commitment and performance. This has affected the morale and motivation of staff. Employees therefore tend to show no interest in the performance management practices in the institution. This can be attributed to a number of challenges such as: the lack of regular feedback from supervisors, thus employees do not receive feedback after performance appraisal; the lack of reward and sanctions in place; instead of a face to face approach to the performance appraisal by both employee and supervisor, it is done separately; and moreover training programs are not linked to performance appraisal reports. There is therefore the need for an in-depth investigation to unravel the reasons for the poor implementation of the performance management system at UHAS.

Moreover, a scan of the literature on performance management shows very few comprehensive studies on the critical elements for the successful implementation of performance management in the public sector, particularly higher education institutions in Ghana. This study thus sought to address this important gap or deficit by exploring the processes, prospects and constraints in employee performance management within a University work setting using the University of Health and Allied Sciences as case study.

The study will outdoor the challenges faced by both management and staff in the implementation of performance management to management of the system as well as help the institution as regards the most likely remedies to the various implementation challenges confronting the system. Again, it will help other institutions, both private and public realize the contribution of performance management systems to human resource 
management in organizations. Following this knowledge organizations will be committed to either implementing or enhancing already existing performance management related programmes.

\section{Material and Methods}

\subsection{Data Collection Technique}

This study employed qualitative design using a descriptive approach to narrate the various successes, prospects and challenges of the system in the university. It uses strategies of inquiry such as narratives, phenomenologies, ethnographies, grounded theory studies, or case studies. Using this subjective methodology aided the researcher to employ open-ended means and ask intriguing questions which afforded respondents the opportunity to freely provide answers to the various questions posed in relation to the objectives.

The study utilized both primary and secondary data. Primary data are those collected by first-hand experience by a researcher. It usually includes data gathered from experiments, survey and structured interviews based on questions set on the various objectives of the study. On the other hand, secondary connotes information derived from already existing materials and people. It included organization records, academic literature, reports, newspapers, articles, journals, internet sources amongst others.

The target population for the study were key stakeholders in the implementation process of performance management system in the school, thus senior staff and junior staff members of University of Health and Allied Sciences. Both purposive and convenient sampling technique were employed in specifically identifying, selecting and interviewing heads of various departments who are raters in the implementation processes of the system who have much deeper understanding of the system and are known.

Ten (10) Administrative senior members who are the raters were selected and interviewed and fifteen (15) senior staff who are the appraisees were also selected and interviewed. The raters were staff under various departments or units as Human Resource, the Vice Chancellors Office, Academic office, Internal office and the Finance. The appraisee will be selected from the various offices at purposively for the interview. The choice for these group of employees in the study was due to the fact that, they are actual raters and appraise in the performance management system at the university who have accumulated several levels of experiences managing and going through the system.

\section{Results and Discussion}

Data were derived from various staff, departments and units of the University's operation. In all, a total of twenty-five (25) respondents with vast years of experience, deeper understanding of the performance management system and ranging from different departments of the University participated in the study. Specifically, respondents ranging from human resources, academic affairs and quality improvement units, finance, office of the Vice Chancellor (VC), office of the registrar, various staff under different faculties of the university, and admissions office/departments formed part of the research work.

The findings from the research work is organized under the following headings; socio demographic characteristics of respondents, analysis of the qualitative data, respondents understanding of performance management systems, prospects of performance management System at UHAS, processes of implementation of performance management systems at UHAS, implementation challenges facing Performance Management System at UHAS, and critical success factors for improving performance management systems at UHAS.

Respondent's socio demographic information is grouped into the following sections; sex, marital status, level of education, departments and their number and duration of service in the university. Data for the study indicates fifteen (15) males of the total respondents' size whereas the female respondents took a smaller frequency of 10. On the data of marital status and educational level of respondents in the study respectively, seventeen (17) respondents were married whereas eight (8) were single. Moreover, on educational level of respondents, ten (10) were post graduate degree holders and thirteen (13) were graduate degree holders. More so, two (2) either holds diploma or certificate in their respective disciplines.

Table 1 presents results regarding the primary data gathered on department/units of operations of the various respondents in the University, information indicates the office of the $\mathrm{VC}$ and human resources department each contributed three (3) number of respondents taking each in the entire respondent's ratio whereas the office of the registrar, finance department and members of various faculties each contributed four (4) respectively from the total ratio. On the other hand, the academic units took on the largest share of respondents as it contributed five (5) with the admissions office being the least contributory department or unit to the study, with just two (2) respondents.

Table 2 shows the data on duration of service at the university. Whereas fifteen (15) of the employees who participated in the study have served between years of 1-3, ten (10) on the other hand has been with the institution running from between 4-6 years of service. 


\subsection{Understanding of performance management system in UHAS}

In relation to examining respondents understanding of performance management system, which would help set the ground for further interrogations, respondents were asked of their view or understanding of the concept of performance management and its practice in the university. Regarding the various perspectives of the concept of performance management and its practice in the university, respondents gave varying conceptions of the term but with quite similar meanings.

Of a total of 25 respondents, five (5) of the entire respondents' ratio explained the concept as being the "process where employees' productivity is assessed with a further reference to training". On the part of this group of respondents, the system connotes a process where each individual in the university or organization is checked as regards his/her contribution to the productivity of the school taking into consideration his roles and responsibilities assigned.

Similarly, five (5) respondents explained the concept of performance management in the university for been the "process of assessing the performance of workers with the view to identifying the lapses in performance of duty". Accordingly, this category of respondent added, "when we refer to the concept of performance management, it usually embodies the development and institution of schemes, systems and/policy where in organizations management takes the necessary procedures, actions and means to identify the weakness on the part of employees and thus affects the quality and efficiency of work they do. Management thus institute means like training programmes to rectify or resolve the weaknesses to the effectiveness of various employees"

Again, whereas seven (7) respondents identified performance management to mean the process "that examines efficiency on the job", eight (8) explained it to mean "the mechanism used by the employer to find out how competent the employees are in organization". A clear examination of these two different conceptions of performance management brings to the fore that, performance management aims to basically examine the extent of efficiency or competency of various employees in the university taking into account their various job descriptions, skills and knowledge. Juxtaposing the seemingly different conceptions but with similar meanings from the respondents, it indicates clearly that, respondents have greater understanding of the process and concept of performance at the university and other organizations in general.

\subsection{The prospects and processes of performance management system at UHAS}

Concerning the primary data gathered on the prospects and processes of performance management system at UHAS, the following summary is made; First, in the case of the prospects, the data gathered indicates, performance management at the university has brighter future and possibility of succeeding to aid in the attainment of the school's long-term visions as well as producing high class graduates in various fields.

Prerequisite factors present for the future sustenance of the system, are; the acceptance of the system by the entire employees of the university. This they explained that, all employees have embraced the idea of performance management as a system of managing the human resource capacity of the university. Thus, the system would also help in enhancing their capabilities and developing their career. They have thus accepted it fully for implementation and this will aid in maintaining it.

Moreover, on the prospects is the issue of the presence of a policy framework which has been embedded in the entire institutional management framework and which makes the performance management system in the institution a broader organizational process and not an ordinary department plan. This thus would ensure the university committing resources to its ideals thus making it sustainable in the future.

As regards data gathered on processes of implementation of performance management system, all twentyfive (25) respondents opined on the following; the setting up of departmental goals, meeting of heads of department to complete appraisal forms.

On the process of setting up departmental goals, respondents explained that, the heads of department taking into account the role or job description of the particular department juxtaposing the broad institutional goals, will develop basic goals and visions for attainment by the department with the human resource department. It is based on such departmental and broader institutional goals that appraisal depends on largely. Concerning the second process of meeting, the departmental heads will thus hold discussions with various employees on the goals set. This is to introduce employees to organizational and departmental goals meant to be achieved.

The final process is the period of appraisal form filling, where the human resource department yearly will bring the appraisal form to various department for individual employees to fill based on their job descriptions taking into account the involvement of the heads of department on decision making reading the filled-in appraisal form. All filled-in forms are returned to the human resource unit for consideration and further action.

\subsection{Successes of performance management system at UHAS}

In the case of findings on the successes of the PMS in the school, it is important to underscore the fact that, only twenty-three (23) respondents with a percentage of $92 \%$ were convinced of the system to have contributed to the growth and performance of the university. Accordingly, they made mention of identification of employee needs, 
improvement in service delivery, attainment of accountability, promotional benefit and effective human resource management.

In the case of identification of employee needs as significance of the system in the school, respondents explained of the system through its process of appraisal which reveals the weaknesses, strengths and capabilities of various staff in the school. With such revelations, the various areas of needs as regards the capabilities of individual employees is brought bear for further consideration and improvement.

On improvement in service delivery, the data suggest, with the identification of employee weaknesses as regards their performance at work, and the institution of appropriate schemes and measures to dealing with such career problems, employees are well positioned to work effectively and efficiently resulting in better service delivery at work.

On accountability and promotional benefit, respondents stated that, the system has created a platform of performance contract where employees are made aware of a period of accountability as regards their work and thus increase their sense of efficiency and effective performance as well as serving as a means for helping in the promotion of employees as employees who score better ratings through PMS are regarded as efficient enough.

Moreover, on efficient management of human resources, data indicates the system has enabled the human resources department to collectively gather performance data of all employees whilst aiding in the development of job descriptions for individual employees in the school.

\subsection{Challenges of performance management system at UHAS}

In the case of the implementation challenges of the system, respondents explained the system is bedeviled with the issue of annual assessment and lack of feedback. According to all respondents, performance management system in the school has not had a system of feedback where after appraisal, employees are not communicated to as regards their performance and capability weaknesses and thus affects the effectiveness of the entire process as they do not know where they fall short or otherwise.

Moreover, the system has just taken the form of a mere appraisal as against the proposed and institutionalized system of performance management. As such, members do not go through the rigorous and complete cycle of performance management in the school. Further, according to the data, most employees do not have adequate sensitization and knowledge of the system with the system being again fraught with bias during rating process. Moreover, there is the problem of the system being done just for purpose of aiding promotion as promotional process in the university requires employees' performance records. These presence conditions of the system, puts it into a challenging situation thus eroding its required and expected effectiveness.

\subsection{Critical Success Factors for effective performance management system}

On the objective of examining the likely critical success measures for the system's effectiveness, all the twentyfive (25) representing 100\% response rate in the study agreed that, for the system to be fully operational and effective, certain necessary critical measures must be instituted. Among the list of essential factors for the effectiveness of the system as indicated by the primary data gathered includes but not limited to; the presence of a feedback system, presence of effective communication or sensitization on the programme, regular appraisal system as against irregular and annual appraisal system and the presence of effective supervision regime during performance evaluation processes.

\section{Conclusion}

This study thus set out to assess the prospects, successes and implementation challenges of the introduced performance management of UHAS. The study concludes that, even though there system has been faced with several challenges which in a way has reduced the full realization of impacts, it has on the other hand chopped some successes so far. The study has established that, performance management system at UHAS has brighter prospects in future and that, the implementation of the system follows sequential order. In other words, the system's implementation follows a particular process. Moreover, the study has found that, the system has been beneficial in the areas of human resource management, accountability attainment, employee needs identification, service delivery and promotion of employees. Similarly, the study identified annual assessment, assessment done for promotional purposes, performance appraisal as against actual performance management system and absence of feedback as impediments to the success of the system.

Again, the study identified the presence of a feedback system, presence of effective communication or sensitization on the programme, regular appraisal system as against irregular and annual appraisal system and the presence of effective supervision regime during performance evaluation processes as necessary conditions for attaining effective and efficient performance management system in the university.

\subsection{Policy Implementation and Recommendations}

The performance management system has gained some form of successes whilst having a brighter future. 
Despite these, the system has several implementation challenges. Based on this, the following recommendations are made;

First, managers of performance management system, particularly, the human resource department, should institute feedback system as part of the effort to attaining efficient and effective performance management system in the school. This should be done by developing channels and mechanism of communication which will seek to address various findings during appraisal to the individual employee.

Secondly, the university should develop a fully fletched performance management system rather than mere annual appraisal system of managing human resources. In other that the benefit of performance management systems is realized in the school, a concrete system of performance management which will involve employees at each stage and embody a complete set of the stages in the performance management cycle should be instituted. Finally, the university should educate employees and sensitize them on the entire performance management system. Sensitization on the system should focus on the goals, objectives and the processes of the system's implementation.

\section{References}

Abdul Hamid, A.S. (1996). The civil service: Towards a new era. Kuala Lumpur: Pelanduk Publications.

Abdul Manap, N. (1996) 'Performance evaluation: Finance and non-finance', unpublished Master's thesis, School of Management, University Utara Malaysia, Kedah, Malaysia.

Adams, J.S. (1963) 'Towards an understanding of inequity'. The Journal of Abnormal and Social Psychology, Volume 67(5), pp. 422-436.

Afsaneh, N (1993) 'Integrating leadership and strategic management in organizational theory'. Canadian Journal of Administrative Science. 10 (4), pp. 297-307.

Aguinis, H. (2013). Performance management (3rd ed.). Upper Saddle River, NJ: Pearson Prentice Hall.

Aguinis, H., Gottfredson, R. K. \& Joo, H. (2012). Delivering effective performance feedback: The strengthsbased approach. Business Horizons, 55, 105-111

Ahmad, R and Ali, N.A (2004) 'Performance appraisal decision in Malaysian public service'. The International Journal of Public Sector Management, Vol. 17, No.1, pp. 4864.

Armstrong, M. \& Baron, A. (2005). Managing performance: performance management in action. CIPD (Chartered Institute of Personnel and Development). London.

Camardella, M. J. (2003). "Effective Management of the Performance-Appraisal Process." Employment Relations Today, 30(1), 103-107.

Cocca, P., and Alberti, M. (2010). "A Framework to Assess Performance Measurement Systems in SMEs." International Journal of Productivity and Performance Management, 59(2), 186-200.

den Hartog, D. N., Boselie, P., and Paauwe, J. (2004). "Performance Management: A Model and Research Agenda.” Applied Psychology: An International Review, 53(4), 556-569.

Fletcher, C. (2001), "Performance Appraisal and Management: A Multi-Level Analysis." Journal of Occupational and Organizational Psychology, 73, 473-487.

Kamoche, K. (2011). Contemporary developments in the management of human resources in Africa. Journal of World Business, 46(1), 1-4.

Kaplan, R. S. "Strategic Performance Measurement and Management in Nonprofit Organizations." Nonprofit Management and Leadership, 2001, 11(3), 353-370.

Locke, E. A. and Latham, G. P. (2002). Building a practically useful theory of goal setting and task motivation: a 35-year odyssey, American Psychologist, 57, pp. 705 - 17.

Locke, E. A., Shaw, K. N., Saari, L. M. and Latham, G. P. (1981). Goal setting and task performance: 1969 1980, Psychological Bulletin, 90, pp. $125-52$.

Matland, "Synthesizing the Implementation Literature: The Ambiguity-Conflict Model of Policy Implementation," Journal of Public Administration Research and Theory, 5 (April, 1995), pp. 145-174.

Mento, A. J., Jones, R. M., and Dirndorfer, W. (2002). "A Change Management Process: Grounded in Both Theory and Practice." Journal of Change Management, 3(1), 45-59.

Mohd Zin, H. (1998) 'Teacher perception towards performance appraisal system', unpublished Master thesis, University Utama Malaysia, Kedah, Malaysia

Mohd. Salleh, L. (2005) 'High/Low Context Communication: The Malaysian Malay Style', Proceedings of the 2005 Association for Business Communication Annual Convention. Ohio University.

Rowley, C (2002) 'Management in Korea: Background and traditions', Financial Times Mastering Management Online, December-January, Issue 9, pp. 1-3.

Rowley, C and Bae, J (2001) 'The impact of globalisation on HRM: The case of South Korea', Journal of World Business, 36 (4), pp. 402-428

Waddell, D. M., and Sohal, A. S. (1998). "Resistance: A Constructive Tool for Change Management." Management Decision, 36(8), 543-548. 
Winstanley, D., and Stuart-Smith, K. (1996). "Policing Performance: The Ethics of Performance Management." Personnel Review, 25(6), 66-84.

\section{Appendix}

\section{Interview Guide for Data Collection}

\section{Objective}

This study aims to collect data for an academic research work on the topic assessing the Processes, Prospects and Challenges in the Implementation of Employees Performance Management System/performance appraisal' in this institution. Please read each question carefully and answer it according to how you personally feel about it. There are no RIGHT or WRONG answers. For the study to be meaningful, it is important that you complete all the questions.

In accordance with the ethics of behavioral science research, individual responses will be completely CONFIDENTIAL. Your organization will NOT have access to the individual responses provided. Instead, responses will be considered collectively to determine the processes, prospects and challenges in the implementation of performance management /performance appraisal system.

\section{Background Information}

1. How long have you been working in this institution?

2. What role do you play in this institution? (Job responsibilities)

To assess the processes in the Implementation of Performance Management/Performance Appraisal system

1.What is your Understanding of PM/PA system?

2. Can you identify some of the processes used in the implementation of PM/PA system in this institution?

.

3. How does the PM/PA system works in this institution?

4. To the best of your Knowledge what are the process the institution uses in the implementation of the PM/PA system?

5.What is the purpose/objectives of the performance management system?

\section{To identify the prospects in the implementation of PM/PA system}

1. What success have been achieved since the implementation of the PM/PA system? 
2. What likely benefit have been derived by the institution after going through the implementation of the $\mathrm{PM} / \mathrm{PA}$ ?

3. What likely benefit have been derived by the employees after going through the implementation of the $\mathrm{PM} / \mathrm{PA}$ ?

\section{To explore the challenges in the implementation of PM/PA system}

1. What are some of the challenges management faces in the implementation of the PM/PA system?

2. What measures can be taken to deal with these challenges?

3. What are some of the solutions towards resolving the challenges in the implementation of PM/PA system?

4. What challenges does employees faces during the implementation of the PM/PA system?

5. What solution/remedies would you recommend towards resolving these challenges?

To identify the critical success factors in the implementation of PM/PA

1. What conditions must be present if this PM/PA system is successful?

2. What necessary steps must be taken to enhance the successful implementation of the PM/PA system?

3. What are some of the success chalked in the implementation of the PM/PA system?

Table 1. Number of Respondents from Various Departments and Offices

\begin{tabular}{|c|c|c|}
\hline Departments/Offices & Number & Percentage \% \\
\hline Office of the VC & 3 & $\mathbf{1 2}$ \\
\hline Office of the Registrar & $\mathbf{4}$ & $\mathbf{1 6}$ \\
\hline Human resources & $\mathbf{3}$ & $\mathbf{1 2}$ \\
\hline Academic affairs & $\mathbf{5}$ & $\mathbf{2 0}$ \\
\hline Finance & $\mathbf{4}$ & $\mathbf{1 6}$ \\
\hline Faculty staff members & $\mathbf{4}$ & $\mathbf{1 6}$ \\
\hline Admissions office & $\mathbf{2}$ & $\mathbf{8}$ \\
\hline Total & $\mathbf{2 5}$ & $\mathbf{1 0 0}$ \\
\hline
\end{tabular}


Table 2. Duration of Service in the University

\begin{tabular}{|c|c|c|}
\hline Years & Number & Percentage \% \\
\hline $1-4$ & 15 & 60 \\
\hline $5-7$ & 10 & 40 \\
\hline Total & 25 & 100 \\
\hline
\end{tabular}

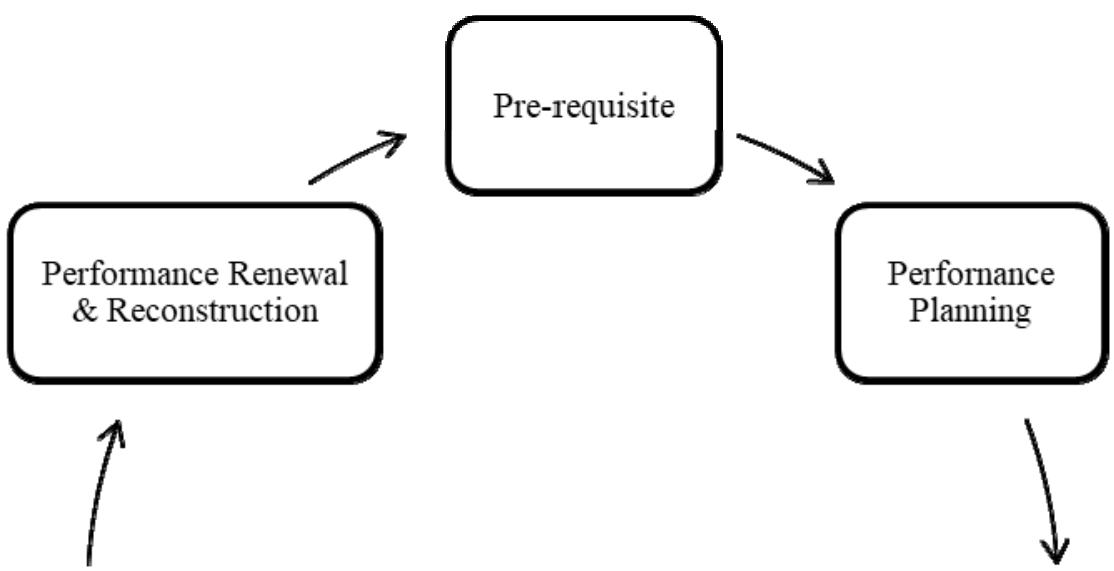

\section{Compensation, Reward \& Punishment}
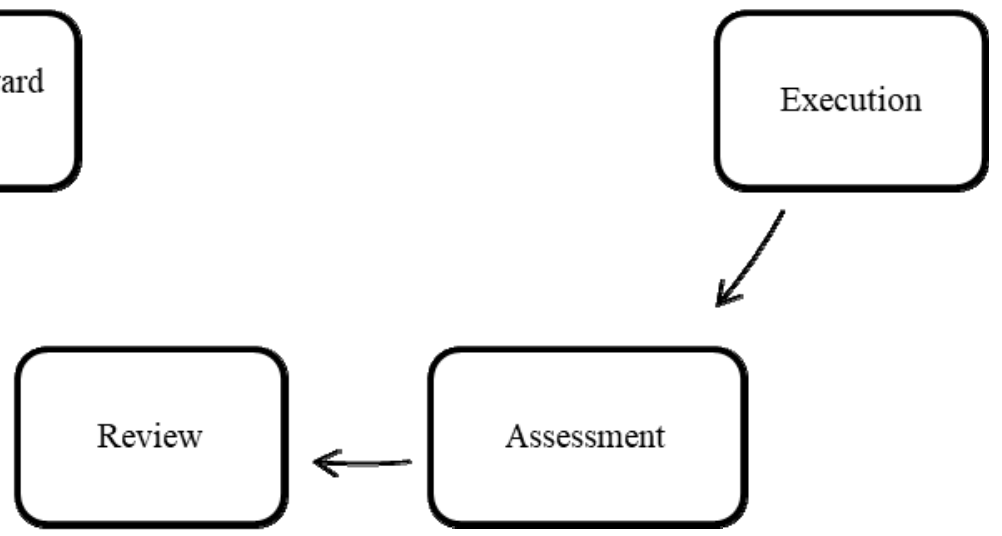

Figure 1. A modified performance management process 